\title{
EFFECT OF MANGOSTEEN EXTRACT ON NEUROINFLAMMATION IN RAT MODEL OF ACUTE TRAUMATIC BRAIN INJURY
}

\author{
ANDRE MAROLOP PANGIHUTAN SIAHAAN ${ }^{1 *}$, SARMA LUMBANRAJA ${ }^{2}$ \\ ${ }^{1}$ Department of Neurosurgery, Medical Faculty, Universitas Sumatera Utara, Medan, Indonesia. ${ }^{2}$ Department of Obstetrics and \\ Gynaecology, Medical Faculty, Universitas Sumatera Utara, Medan, Indonesia. Email: andremarolop@gmail.com
}

Received:04 January 2019, Revised and Accepted: 23 January 2019

\begin{abstract}
Objective: Traumatic brain injury (TBI) is one of the major health problems regarding morbidity and mortality, especially in productive ages. Following primary injury, there is a secondary insult, resulting in oxidative stress, neuroinflammation, and cell death. Mangosteen is a powerful natural antioxidant and anti-inflammation that also has neuroprotective property. The aim of this study was to explore the effect of mangosteen extract (ME)on neuroinflammation following TBI.
\end{abstract}

Methods: A total of 30 Sprague-Dawley rats were randomized into three treatments group, i.e., sham-operated controls, closed head injury (CHI), and treatment group. In the treatment group, we gave ME once daily every day after CHI for 7 days. As oxidative process marker, we investigated malondialdehyde (MDA) expression. As neuroinflammation marker, we investigated glial fibrillary acidic protein (GFAP) and CD-68.

Results: TBI increased the expression of GFAP and CD-68, but not MDA. There was significant GFAP expression difference between treatment group and $\mathrm{CHI}$ group. Regarding the expression of CD-68 and MDA, there was no significant difference between treatment and CHI group.

Conclusion: Mangosteen extract supplementation decreased GFAP expression significantly after TBI.

Keywords: Mangosteen extract, Traumatic brain injury, Neuroinflammation.

(C) 2019 The Authors. Published by Innovare Academic Sciences Pvt Ltd. This is an open access article under the CC BY license (http://creativecommons. org/licenses/by/4. 0/) DOI: http://dx.doi.org/10.22159/ajpcr.2019.v12i3.24267

\section{INTRODUCTION}

Traumatic brain injury (TBI) is one of the major health problems regarding morbidity and mortality, especially in productive ages. In the US, TBI was the diagnosis in $>282.000$ hospitalization and 2.5 million emergency department visits in 1 year and contributed to the death of nearly 50,000 people [1]. The in-hospital mortality of moderate and severe TBI was around 31\% [2]. Among the survivors, chronic disability is a common finding. The total economic burden is estimated $>\$ 37.8$ billion, resulted from direct treatment at the hospital and long-time care, premature death, and work absence or disability [3].

TBI is initiated with mechanical force to the head that triggers a diverse series of cerebral events. These diverse events are the main challenge in TBI treatment. Disruption of blood-brain barrier integrity which leads to vascular leakage, edema, hemorrhage, stretching of axonal fibers, and disruption of junctions between white and gray matter is some of the primary pathologic mechanisms that will be accompanied by cellular and molecular cascades, known of secondary brain injury. N-methyld-aspartic acid (NMDA) receptor activation leading to excitotoxicity, excessive nitric oxide generation, and free radical-mediated oxidative stress are some of the processes that happened in secondary brain injury. After TBI, there is an excessive generation of oxidative stress parameters such as lipid peroxides [4]. All of these secondary processes will lead to inflammation and neural death.

Inflammatory response following TBI is a common feature that is characterized by the cellular activation of astrocytes, microglia, monocytes or macrophages, neutrophils, and T cells after the release of damage-associated molecular pattern molecules [5]. Concurrently, proinflammatory and anti-inflammatory cytokines will compete, either to promote or terminate the inflammatory response. Inflammation itself could be beneficial by promoting debris clearance and neural regeneration. On the other side, it can also mediate neural death and chronic degeneration [6].

Herbal remedies become popular in neural disease. They are proved to have affect in slowing the neurodegenerative process and have fewer side effects [7]. Mangosteen, Garcinia mangostana linn, is a kind of fruit that can be easily found in South and Southeast Asia. The fruit is dark purple or reddish in color and contains edible white pulps inside that are soft and juicy. The pericarp of these fruits has been used for centuries in South and Southeast Asia for the treatment of skin infection, wounds, diarrhea, and cholera [8]. Alpha mangosteen, xanthone derived from this fruit, will attenuate brain inflammation that induced by peripheral lipopolysaccharide in rats [9]. As other traditional drug, one of the main properties of mangosteen is in reducing oxidative stress [10]. This present study was undertaken to explore the potential effects of mangosteen extract (ME) with the respect of astrogliosis, microglia activation, and malondialdehyde (MDA).

\section{METHODS}

\section{Animals}

A total of 30 male Sprague-Dawley rats $(n=30)$ weighing 250-400 g were housed in polycarbonate cages with a $12 \mathrm{~h}$ light and dark cycle. Food and water were given ad libitum, and the experiment was undertaken after 2 weeks acclimatization period. This protocol was approved by an Institutional Review Committee of Universitas Sumatera Utara, Medan, Indonesia.

\section{Experimental groups}

The rats were randomly divided into three groups, i.e., sham-operated group, closed head injury (CHI) group, and treatment group. Shamoperated rat underwent anesthesia and surgery, without trauma and treatment. The CHI group received trauma only. The treatment group underwent trauma protocol and was given the drug. 


\section{Drug treatment}

Mangosteen was taken from Malang Regency in East Java, Indonesia. Dried-clean pericarp was placed in $70 \%$ ethanol. The macerate filtrate was evaporated using rotary evaporator. From $100 \mathrm{~g}$ dried mangosteen pericarp, $50 \mathrm{cc}$ ME was obtained. ME (100 mg/kgBW) was given for 7 days consecutively from trauma procedures.

\section{Weight drop closed brain injury model}

Unilateral focal brain injury was induced on the right frontal area using a rat model of CHI, performed with the modified Feeney's weight-drop protocol [11]. All animals were weighed directly before protocol. As anesthesia, we gave ketamine $\mathrm{HCl}$ intramuscular $(100 \mathrm{mg} / \mathrm{kgBW})$. The scalp was opened on the right frontal, but we did not do any craniotomy. Then, the rats were placed securely in a stereotactic apparatus. A 40-g mass was dropped from $1.5 \mathrm{~m}$ height into the exposed skull. Afterward, animals were sacrificed through cervical dislocation. In the positive control group, as well as the treatment group, subjects were divided into three groups based on sacrificial timing, i.e., $1^{\text {st }}, 3^{\text {rd }}$, and $7^{\text {th }}$ day, respectively. The brains were removed and fixed in $10 \%$ buffered formalin. The specimens were then processed for paraffin-embedded for immunohistochemistry staining preparation.

\section{Immunohistochemistry staining}

As oxidative process marker, we investigated MDA expression. For inflammation, we investigated CD-68 (microglial activation marker) and glial fibrillary acidic protein (GFAP) (astrogliosis marker). The expression of all markers was investigated on paraffin-embedded sections using the avidin-biotin-peroxidase complex method. $5 \mathrm{~mm}$ thick paraffin sections were dewaxed, rehydrated, and microwave for $10 \mathrm{~min}$. The endogenous peroxidase activity of the investigated specimens was blocked with $3 \% \mathrm{H}_{2} \mathrm{O}_{2}$ for $10 \mathrm{~min}$, followed by $25 \mathrm{~min}$ washing with phosphate-buffered saline (PBS). The tissue sections were incubated with normal rabbit serum for $10 \mathrm{~min}$, and then the slides were incubated at room temperature with monoclonal mouse MDA, SOD, AIF, caspase 8, and caspase 9 (Santa Cruz). Sections were washed with PBS and incubated with a secondary antibody for $30 \mathrm{~min}$. Sections were washed twice with PBS, developed with $0.05 \% 3,3$ diaminobenzene tetrahydrochloride for $5 \mathrm{~min}$, and slightly counterstained.

All samples were evaluated by the first author (not blinded to specimen). A positive signal for MDA, CD-68, and GFAP in brain tissue was quantitatively estimated on the basis of the distribution of positive stained cells in the cortical brain. Cell counts were carried out using a light binocular microscope with 1000 times magnification in 20 high power fields.

\section{Statistical analysis}

The total stained cells were reported in the mean and standard error of the mean. When comparisons were made between groups, significance in between-group variability was analyzed using the one-way ANOVA test with Tukey as post hoc test. Differences were considered significant at $\mathrm{p}<0.05$.

\section{RESULTS}

\section{Mortality rate}

Three rats died in this protocol out of thirty rats. Within the control group, two rats died on the $1^{\text {st }}$ and $3^{\text {rd }}$ day. One rat in the ME group died on the $3^{\text {rd }}$ day. There was no mortality in sham-operated control group.

\section{TBI increased expression of GFAP and CD-68}

There was a significant difference in GFAP and CD-68 expression between negative sham group and $\mathrm{CHI}$ group (Fig. $1 \mathrm{~b}$ and $1 \mathrm{c}$ ), but there was no significant difference in MDA expression between negative sham group and CHI group (Fig. 1a).

\section{Mangosteen extract reduced GFAP expression following TBI}

There was significant GFAP difference between $\mathrm{CHI}$ and treatment group (Fig. 1b), but there was no significant difference in MDA and CD68 expression following TBI (Fig. 1b and 1c).

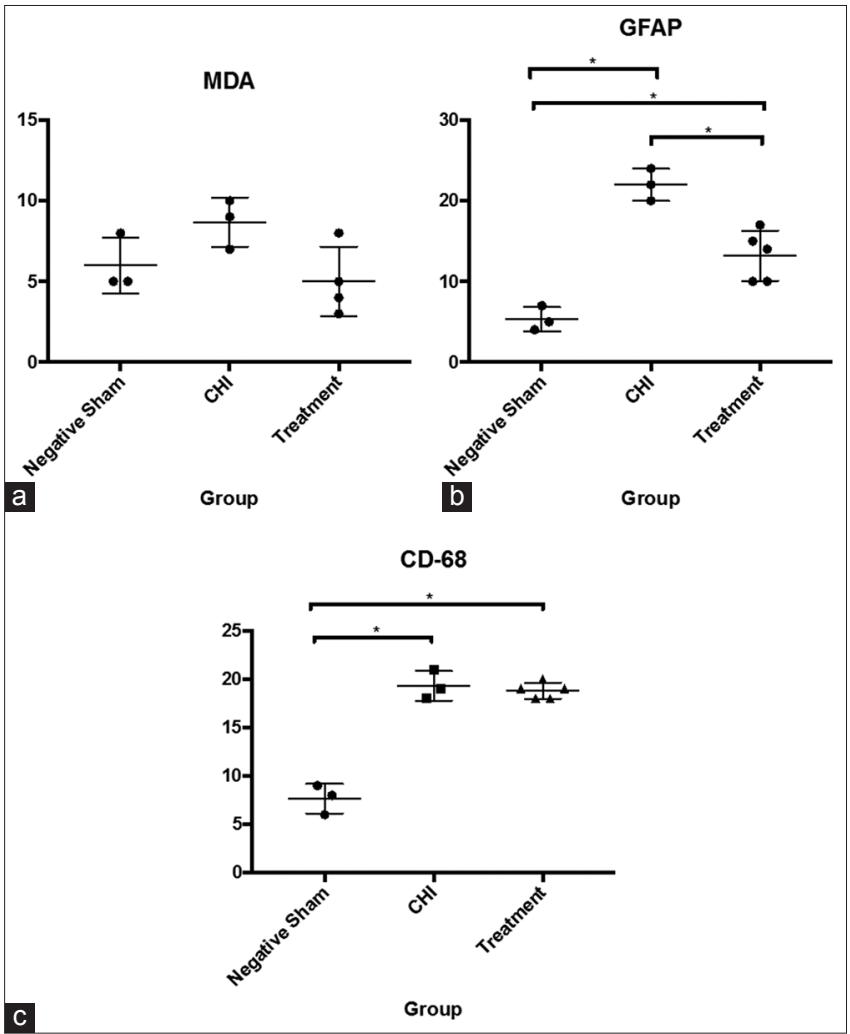

Fig. 1: Malondialdehyde. (a) glial fibrillary acidic protein,

(b) CD-68, and (c) expression in negative sham, closed head injury, and treatment group. Data in mean \pm standard error of the mean. One-way ANOVA. *significant if $p<0.05$

\section{DISCUSSION}

In this study, the effect of ME in TBI was evaluated using immunohistochemistry. We demonstrated that $\mathrm{ME}$ decreased the expression of GFAP, but we did not find a significant effect of ME regarding microglia activation and MDA.

The concept of central nervous system damage-mediated by free radical has been existed for several decades. Exogenous antioxidants have the potential to limit the secondary brain injury and inflammation if given soon after TBI. Due to the high antioxidant activity, herbal products have been advocated in the management of TBI. Some supplementations, such as spirulina and turmeric, have been reported to be a strong antioxidant that has a significant effect in an animal study [12].

Mangosteen has been used as traditional medicine for years. Many reports have been published regarding the pharmacological activities of $\alpha$ and $\beta$ mangosteen, the active substance in mangosteen pericarp [13]. It has a strong effect in reducing the expression of inflammatory mediators, such as tumor necrosis factor- $\alpha$ (TNF- $\alpha$ ) and interleukin- 6 (IL-6) $[14,15]$. Xanthone from mangosteen, especially $\alpha$ mangosteen, inhibits the NMDA and glutamate receptors [16].

Upregulation of GFAP is a common feature following astrogliosis. Reactive astrocytes will release many cytokines and chemokines, such as IL-6, TNF-a, and INF. In damaged neural tissue, reactive astrocytes play critical roles in neuroprotection, blood-brain barrier repair, and regulation of inflammation. Even though, prolonged astrogliosis will result in extensive scar formation chronically [17]. Here, we showed that ME decreased GFAP expression significantly. Long-term effect of this activity cannot be concluded in this research. It became one of this research limitation, i.e, only done in the short term follow-up (7 days). This finding was consistent with the previous study. Supplementation 
of mangosteen pericarp was shown to decrease GFAP expression in transgenic Alzheimer's mice [18].

In this research, ME did not decrease the expression of MDA. MDA is a highly toxic molecule and it has been implicated in a range of disease pathologies by producing oxidative damage in the tissues [19]. Increased of MDA in CHI group imply shift of the oxidative balance in brain to pro-oxidative [20].

We found a trend of decreasing CD-68 expression, although it was not statistically significant. CD-68 actually is a common descriptive marker for microglial function. It is upregulated in actively phagocytic cells [21]. Increased of CD-68 expression in both $\mathrm{CHI}$ and treatment groups implied active phagocytic process following TBI. Other widely used microglia activation markers are

HLA-DR and Iba-1. All these three markers may identify different activation stages of microglia [22]. Microglia activation itself is a double edge sword. It can be useful, but also can be harmful.

The main limitation of this study is short-term follow-up. Neuroinflammation itself can be happened until years after the initial insult. The other limitation of this study is the nature of the TBI process. Using the weight drop models, we could only make focal injury.

\section{CONCLUSION}

ME supplementation decreased the GFAP expression significantly after TBI.

\section{ACKNOWLEDGMENT}

This research was supported of Universitas Sumatera Utara, Medan, Indonesia by a TALENTA 2017 grant to young lecturer.

\section{AUTHORS' CONTRIBUTIONS}

First author (A.M.P.S) initiated and conducted the research. The second author (S.L) conducted animal care and prepared the manuscript.

\section{CONFLICTS OF INTEREST}

The authors declare that they have no conflicts of interest.

\section{REFERENCES}

1. Taylor CA, Bell JM, Breiding MJ, Xu L. Traumatic brain injury-related emergency department visits, hospitalizations, and deaths-United States, 2007 and 2013. MMWR Surveill Summ 2017;66:1-6.

2. Rondina C, Videtta W, Petroni G, Lujan S, Schoon P, Mori LB, et al. Mortality and morbidity from moderate to severe traumatic brain injury in Argentina. J Head Trauma Rehabil 2005;20:368-76.

3. Thurman DJ, Alverson C, Dunn KA, Guerrero J, Sniezek JE. Traumatic brain injury in the United States: A public health perspective. J Head Trauma Rehabil 1999;14:602-15.
4. Blennow K, Hardy J, Zetterberg H. The neuropathology and neurobiology of traumatic brain injury. Neuron 2012;76:886-99.

5. Corps KN, Roth TL, McGavern DB. Inflammation and neuroprotection in traumatic brain injury. JAMA Neurol 2015;72:355-62.

6. Simon DW, McGeachy MJ, Bayır H, Clark RS, Loane DJ, Kochanek $\mathrm{PM}$, et al. The far-reaching scope of neuroinflammation after traumatic brain injury. Nat Rev Neurol 2017;13:171-91.

7. Roy S, Aqasthi H. Herbal medicines as neuroprotective agent: A mechanistic approach. Int J Pharm Pharm Sci 2017;9:1-7.

8. Pedraza-Chaverri J, Cárdenas-Rodríguez N, Orozco-Ibarra M, PérezRojas JM. Medicinal properties of mangosteen (Garcinia mangostana). Food Chem Toxicol 2008;46:3227-39.

9. Nava Catorce M, Acero G, Pedraza-Chaverri J, Fragoso G, Govezensky T, Gevorkian G, et al. Alpha-mangostin attenuates brain inflammation induced by peripheral lipopolysaccharide administration in C57BL/6J mice. J Neuroimmunol 2016;297:20-7.

10. Sairazi NM, Sirajudeen KN, Muzaimi M, Swamy M, Asari MA, Sulaiman SA. Tualang honey attenuates kainic acid-induced oxidative stress in rat cerebellum and brainstem. Int $\mathrm{J}$ Pharm Pharm Sci 2017;9:155-62.

11. Feeney DM, Boyeson MG, Linn RT, Murray HM, Dail WG. Responses to cortical injury: I. Methodology and local effects of contusions in the rat. Brain Res 1981;211:67-77.

12. Bains M, Hall ED. Antioxidant therapies in traumatic brain and spinal cord injury. Biochim Biophys Acta 2012;1822:675-84.

13. Dharmaratne HR, Piyasena KG, Tennakoon SB. A geranylated biphenyl derivative from Garcinia malvgostana. Nat Prod Res 2005;19:239-43.

14. Bumrungpert A, Kalpravidh RW, Chuang CC, Overman A, Martinez K, Kennedy A, et al. Xanthones from mangosteen inhibit inflammation in human macrophages and in human adipocytes exposed to macrophageconditioned media. J Nutr 2010;140:842-7.

15. Bumrungpert A, Kalpravidh RW, Chitchumroonchokchai C, Chuang CC, West T, Kennedy A, et al. Xanthones from mangosteen prevent lipopolysaccharide-mediated inflammation and insulin resistance in primary cultures of human adipocytes. J Nutr 2009;139:1185-91.

16. Leewanich P, Suksamram S. Xanthones isolated from the pericarp of mangosteen inhibit neurotransmitter receptors expressed in xenopus oocytes. J Med Assoc Thai 2015;98 Suppl 10:S118-23.

17. Sofroniew MV. Astrogliosis. Cold Spring Harb Perspect Biol 2014; 7:a020420.

18. Huang HJ, Chen WL, Hsieh RH, Li HM. Multifunctional effects of mangosteen pericarp on cognition in $\mathrm{C} 57 \mathrm{BL} / 6 \mathrm{~J}$ and triple transgenic Alzheimer's mice. Evid Based Complement Alternat Med 2014;2014:813672.

19. Draper HH, Hadley M. Malondialdehyde determination as index of lipid peroxidation. Methods Enzymol 1990;186:421-31.

20. Dalle-Donne I, Rossi R, Colombo R, Giustarini D, Milzani A. Biomarkers of oxidative damage in human disease. Clin Chem 2006;52:601-23.

21. Zotova E, Bharambe V, Cheaveau M, Morgan W, Holmes C, Harris S, et al. Inflammatory components in human Alzheimer's disease and after active amyloid- $\beta 42$ immunization. Brain 2013;136:2677-96.

22. Hendrickx DA, van Eden CG, Schuurman KG, Hamann J, Huitinga I. Staining of HLA-DR, ibal and CD68 in human microglia reveals partially overlapping expression depending on cellular morphology and pathology. J Neuroimmunol 2017;309:12-22. 